\title{
EL NUEVO EDITOR SE PRESENTA
}

\section{THE NEW EDITOR GREETS}

Etapa cumplida, la de Yuri Carvajal, con ahínco desplegando la consigna de establecer y hacer crecer la Revista Chilena de Salud Pública, rescatarla de los avatares administrativos, editoriales y económicos. En sus 60 años de vida, la Revista ha tenido períodos de deriva, de somnolencia y despertares, crepúsculos y alboradas reflejantes de turbulencias que afectaron las dos afiliaciones que reconoce en su título: la Escuela que es su nido, la salud pública nacional que la cobija. En los cuatro años de gestión, el editor saliente logró establecer tres atributos esenciales para un producto académico: la regularidad de su aparición cuatrimestral, el atractivo de una cuidada y seductora presentación, la calidad de sus contenidos. Etapa cumplida que compromete al editor entrante por mantener lo logrado y aspirar a más, tarea nada fácil cuando la vara es alta.

Con ingenuo optimismo, Yuri propuso al nuevo editor, confiando que la trayectoria común de amistad e intereses salvaguardaría los atributos de la Revista, y que la dinámica de gestión no sería defraudada. Las sinceras protestas de insuficiencia no fueron escuchadas: el director de la Revista y el director de la Escuela compartieron la propuesta.

Yuri no se distancia, se resitúa: física y laboralmente en la Patagonia; en lo editorial, asumiendo como editor de Reseñas. Los reconocimientos y agradecimientos que detalló en su editorial de despedida, son también los míos, tal vez más comprometidos por cuanto asumí el cargo con la condición de contar con el apoyo paritario de todos los nombrados.

La orientación de la Revista permanece inalterada, así como la intención de reconocer cada vez más que la salud pública ha de ser respetuosa de las ciencias "duras", a tiempo de comprometer su pasión con las disciplinas sociales. La Revista es un atril, empeñada en acoger un amplio espectro de musicalidad.

El cambio de editor no es una voltereta, no es una discontinuidad. Pero un editor dedicado ha de introducir sus propios matices, olores y sabores que lo caracterizan, aquello que Yuri sutilmente mencionó como "diferencias conceptuales”. Tal vez, y es de esperar, no sea más que una diversidad de sensibilidades, en un rango que mantenga el espíritu amigable entre todos nosotros y hacia quienes validan la existencia de la Revista: sus lectores. "Volver al cuerpo y la vida: que den sentido a la Tierra, un sentido humano" (Nietzsche). 